\title{
High serum bicarbonate and adverse outcomes in hemodialysis patients
}

\author{
Gonçalo Ávila, Ivo Laranjinha, Patrícia Matias \\ Nephrology department, Hospital de Santa Cruz - CHLO, Carnaxide
}

\section{ABSTRACT}

Metabolic acidosis is a usual complication of progressive chronic kidney disease and is associated with morbidity and mortality. The correction of metabolic acidosis is a main goal of dialysis. In prevalent hemodialysis patients, acid-base homeostasis depends on many factors, mainly net acid production, amount of alkali given by the dialysate bath and duration of the interdialytic period.

At present, the main concern in prevalent hemodialysis patients is not over patients with metabolic acidosis, but rather about the growing numbers of patients with metabolic alkalosis. Several large cohort studies have shown significant associations between high predialysis bicarbonate, as well as blood $\mathrm{pH}$, and morbidity and mortality risk. Based on recent guidelines, we should keep predialysis serum bicarbonate concentrations at $24-26 \mathrm{mEq} / \mathrm{L}$, although this is opinion-based and there is no consensus on the issue. Furthermore, there should be specific focus on the patient's nutritional status and reversible comorbidities.

Keywords: bicarbonate; hemodialysis; metabolic alkalosis; mortality

\section{INTRODUCTION}

Metabolic acidosis is a feature of progressive chronic kidney disease and end-stage renal disease and it is associated with adverse outcomes, such as morbidity, hospitalization and mortality. ${ }^{1}$ The correction of metabolic acidosis in prevalent hemodialysis (HD) patients is achieved through a base supply in the dialysate during dialysis treatments.

As of today, most patients are treated with a bicarbonate dialysate rather than acetate. This dialysate is achieved with a 3-stream method using a proportioning dual-concentrate system that mixes water with a base-concentrate and an acid-concentrate. The latter contains an organic acid, such as sodium diacetate, that is added to prevent insoluble precipitation of calcium carbonate, and that is ultimately converted to bicarbonate in the liver, thus increasing the total amount of base in the final dialysate (usually $2-8 \mathrm{mEq} / \mathrm{L}$ of acetate). ${ }^{2}$

Dialysate bicarbonate $\left(D_{\mathrm{BIC}}\right)$ prescription varies significantly around the world, usually ranging from $30 \mathrm{mEq} / \mathrm{L}$ up to $40 \mathrm{mEq} / \mathrm{L} .{ }^{3}$ Average $D_{B I C}$ is lower in Europe and Japan and is higher in the USA. Additionally, some hemodialysis centers individualize $D_{B I C}$ prescriptions, whereas others prescribe the same $D_{B I C}$ for all patients.

\section{ACID-BASE BALANCE IN PREVALENT HD PATIENTS}

The ideal goal for acid-base management in HD patients is to prescribe a $D_{B I C}$ that corrects metabolic acidosis and prevents predialysis acidosis, while avoiding postdialysis alkalosis. ${ }^{4}$
The assessment of acid-base status in prevalent HD patients is currently based on measurements of predialysis serum total $\mathrm{CO} 2$ (TCO2) in venous blood, which includes serum bicarbonate and dissolved $\mathrm{CO} 2(\mathrm{TCO} 2=[\mathrm{HCO}-]+0.003 \times \mathrm{PCO} 2)$. Under most conditions, this means that TCO2 is approximately $1 \mathrm{mEq} / \mathrm{L}$ higher than serum bicarbonate. ${ }^{5}$ Blood $\mathrm{pH}$ and $\mathrm{PCO} 2$ are not routinely assessed, so we can only infer if the patient is acidotic or alkalotic based on serum bicarbonate.

Although $D_{B I C}$ directly influences predialysis serum bicarbonate, there are many other important determinants, such as protein intake, interdialytic weight gain, residual diuresis, time since last dialysis and the use of sevelamer as a phosphate binder. ${ }^{6-10}$ Namely, endogenous acid production in HD patients is largely determined by protein intake. A typical Western diet includes a significant amount of animal protein that generates predominantly acidic by-products. ${ }^{6}$ Indeed, there is evidence of inverse associations between predialysis serum bicarbonate and several nutritional indicators, such as serum phosphorus, potassium, urea, creatinine, albumin, body mass index and normalized protein catabolic rate (nPCR). ${ }^{11-14}$

Interdialytic water gain is inversely associated with predialysis serum bicarbonate. An increase in fluid retention between HD treatments lowers predialysis serum bicarbonate by diluting alkali stores. ${ }^{7}$ Predialysis serum bicarbonate is also lower at the beginning of the week by about $1 \mathrm{mEq} / \mathrm{L}$ because of longer interval between $\mathrm{HD}$ sessions. ${ }^{8}$ The use of sevelamer hydrochloride is associated with lower serum bicarbonate, ${ }^{9}$ whereas sevelamer carbonate has the opposite effect. ${ }^{10}$

Bicarbonate dialysance behaves differently from urea dialysance. Serum bicarbonate rapidly increase during the first 2 hours of dialysis and its 
dialysance continuously decays thereafter. This is due to organic acid production induced by the added bicarbonate, which limits further increases in serum bicarbonate. ${ }^{11}$ At the end of the dialysis session, serum bicarbonate is usually 4 to $7 \mathrm{mEq} / \mathrm{L}$ less than $\mathrm{D}_{\mathrm{BIC}} .^{15}$ Park et al. ${ }^{16}$ showed that lowering $D_{B I C}$ does not meaningfully reduce organic acid generation.

\section{SERUM BICARBONATE AND MORTALITY IN HD PATIENTS}

Over the last few decades, there has been a trend towards a gradual increase in serum bicarbonate levels in prevalent HD patients, and concerns regarding the association between serum bicarbonate, $D_{B I C}$ and mortality have started to arise.

In 1990, Lowrie and Lew ${ }^{17}$ first reported a U-shaped relationship between baseline predialysis serum bicarbonate and mortality, with a higher risk of death when serum bicarbonate was $<17.5 \mathrm{mEq} / \mathrm{L}$ or $>25 \mathrm{mEq} / \mathrm{L}$. The lowest mortality risk was observed in the 20-22.5 $\mathrm{mEq} / \mathrm{L}$ range.

In 2004, Bommer et al. ${ }^{18}$ analyzed data from the Dialysis Outcomes and Practice Patterns Study (DOPPS) from 1996 to 2001 and confirmed a U-shaped curve for the association of serum bicarbonate with mortality and hospitalization. A higher mortality risk was observed for levels of midweek predialysis serum bicarbonate $\leq 16.0 \mathrm{mEq} / \mathrm{L}$ and $>27.0 \mathrm{mEq} / \mathrm{L}$ after adjustment for comorbidities, with the lowest risk for mortality at levels of 20.1-21.0 mEq/L. However, after adjustment for nutritional markers, mortality risk became nonsignificant among patients with bicarbonate levels $>27 \mathrm{mEq} / \mathrm{L}$ while it remained significantly elevated for levels $\leq 17.0 \mathrm{mEq} / \mathrm{L}$. The authors also reported a weak, albeit significant, inverse correlation between predialysis serum bicarbonate and albumin levels and $\mathrm{nPCR}$. This indicates that a greater acid load from higher protein intake contributes to a more expressed acidosis and a positive nitrogen balance contributes to greater serum albumin levels. ${ }^{18}$

In 2006, Wu et.al., ${ }^{19}$ using a DaVita database, studied the association between baseline predialysis serum bicarbonate and 2-year mortality in more than 5000 prevalent HD patients. The lowest unadjusted mortality was associated with predialysis bicarbonate in the 17 to 23 $\mathrm{mEq} / \mathrm{L}$ range, whereas values $>23 \mathrm{mEq} / \mathrm{L}$ were associated with progressively higher all-cause and cardiovascular death rates. This association, however, reversed after case-mix and malnutrition inflammatory complex syndrome (MICS) multivariable adjustment, so that bicarbonate values $>22 \mathrm{mEq} / \mathrm{L}$ had lower death risk. They also found inverse associations between predialysis serum bicarbonate and several nutritional indicators, including serum phosphorus, potassium, and urea levels as well as nPCR.

Fresenius Medical Care North America expressed concern over high DBIC in an internal memo sent to all its units in $2011 .{ }^{20}$ It reported a gradually rising predialysis serum bicarbonate over the years and an unadjusted odds ratio for cardiopulmonary arrest of 6.3 when predialysis serum bicarbonate was above $28 \mathrm{mEq} / \mathrm{L}$. It is important to note that this memo was not peer-reviewed.

In 2013, Tentori et al. ${ }^{3}$ analyzed the DOPPS database once again, this time between 2002 and 2011, which included around 17,000 HD patients, and examined the relationship of $D_{B I C}$ concentration with mortality. While no association between mortality and prescribed $D_{B I C}$ was found in univariable analysis, a slightly (8\%) higher mortality risk among patients prescribed high $D_{\mathrm{BIC}}$ after multivariable adjustment was reported. Interestingly, the higher risk in mortality was driven by an increase in infection-related mortality, and not by cardiovascular (CV) events, as one might have expected.

In 2015, Yamamoto et al. ${ }^{21}$ also examined pre and postdialysis $\mathrm{pH}$, as well as serum bicarbonate and their association with all-cause and CV mortality in more than 15,000 MHD Japanese patients. Population analysis showed that patients with a higher predialysis $\mathrm{pH}$ had a higher frequency of CV diseases and lower frequency of diabetes and showed lower interdialytic weight gain, calcium-phosphorus product, hemoglobin, and nPCR values than patients with a lower predialysis $\mathrm{pH}$. In an adjusted analysis, they found that only a predialysis $\mathrm{pH} \geq 7.40$ was associated with an increased risk for all-cause and CV mortality. As expected, these patients had a higher predialysis serum bicarbonate, but they had lower partial pressure of carbon dioxide (pCO2), suggesting some degree of respiratory alkalosis.

Also, in 2015, Chang et al. ${ }^{22}$ also studied the association of predialysis TCO2 and mortality in a cohort of 1,159 MHD Korean patients. All-cause mortality was increased in patients with predialysis TCO2 $\geq$ $24 \mathrm{mEq} / \mathrm{L}$ in an unadjusted and adjusted model when compared to patients with a lower TCO2. This increased mortality was independent from nPCR level.

\section{HIGH BICARBONATE AND ADVERSE CARDIOVASCULAR EFFECTS}

The association between predialysis serum bicarbonate and CV disease and mortality remains controversial. There are some deleterious consequences of using a higher $D_{B I C}$, but the extent to which they contribute to the increased mortality seen in patients with higher predialysis serum bicarbonate is not yet clear. As Di lorio et.al. ${ }^{23}$ reported, a higher DBIC contributes to an increased QTc interval during $\mathrm{HD}$ session. This occurs mainly because the rise in serum bicarbonate and correction of metabolic acidosis causes a fall in ionized calcium and an intracellular uptake of potassium. As such, the effect of a prolonged QTc is aggravated by a concomitantly low potassium and calcium dialysate concentration. The QTc interval remains increased at least four hours post-HD, increasing the risk of arrythmias. The decrease in serum ionized calcium and potassium caused by high $D_{B I C}$ may also cause a decrease in peripheral resistance, leading to increased frequency of symptomatic hypotension. This was reported in 2003 by Gabutti et al. ${ }^{24}$ However, Viegas et.al. ${ }^{25}$ in 2013 showed that a DBIC of $34 \mathrm{mEq} / \mathrm{L}$ had no association with intradialytic hypotension nor interdialytic weight gain when compared to a $D_{B I C}$ of $30 \mathrm{mEq} / \mathrm{L}$ in MHD patients.

More recently, in 2019, Krahn et al. ${ }^{26}$ investigated the effects of acetate-containing bicarbonate-buffered dialysate on frequency of ventricular arrythmias using a 48-hour Holter monitoring. They concluded that, although higher $D_{B I C}$ was associated with postdialysis metabolic alkalosis, it had no direct association with ventricular arrythmias. 
The association between higher $\mathrm{D}_{\mathrm{BIC}}$ and calcium phosphate precipitation in blood vessels, although plausible, is yet to be studied in detail. In 1995, Harris and colleagues ${ }^{27}$ proposed that early correction of metabolic acidosis at the beginning of dialysis impaired phosphate clearance by increasing its uptake by erythrocytes and subsequently reducing phosphate availability for removal by dialysis, which could be overcome with a modeled-bicarbonate dialysis (lower $\mathrm{D}_{\mathrm{BI}}$ in the beginning of dialysis, gradually increasing until the end). However, they found no difference in phosphate clearance compared to standard bicarbonate dialysis.

\section{CHALLENGES IN INTERPRETING SERUM BICARBONATE IN HD PATIENTS}

Patel et al. $^{14}$ found significant variability in monthly serum bicarbonate measurements among patients receiving HD, despite uniform bicarbonate dialysis prescription. Considering a reference range of $22-26 \mathrm{mEq} / \mathrm{L}$, they reported that approximately $50 \%$ of patients with predialysis serum bicarbonate outside of that range, that would return to normal in the subsequent month even if the clinician took no action regarding $D_{\mathrm{BIC}}$, oral bicarbonate supplementation or phosphate binder prescription. As so, they argue that the decision to alter DBIC should not be made with a single serum bicarbonate value, and that even a 3-month mean could be insufficient.

Measurement of blood $\mathrm{pH}$ and $\mathrm{pCO} 2$ would provide additional useful data. Prevalent HD patients can have a wide range of acid-base disorders for any given predialysis bicarbonate value. ${ }^{8,21}$ It is important to note that primary respiratory alkalosis or acidosis cannot be inferred by serum bicarbonate in chronic HD patients in the absence of kidney function. These disorders are likely to be associated with an increase in mortality risk in this population. ${ }^{5}$ As observed by Marano and colleagues, ${ }^{8}$ approximately one-fourth of patients with serum bicarbonate $<20 \mathrm{mEq} / \mathrm{L}$ had $\mathrm{pH}$ values $>7.40$ due to coexisting respiratory alkalosis. Conversely, almost half of the patients with predialysis serum bicarbonate $>25 \mathrm{mEq} / \mathrm{L}$ had $\mathrm{pH}<7.40$ due to a complicating respiratory acidosis. If the clinician were to alter $D_{B I C}$ solely based on the serum bicarbonate value, they could be worsening their alkalemia and acidemia, respectively. As such, a complete assessment of acid-base status should be made before adjusting $D_{B I C}$ in hemodialysis patients.

\section{CONCLUSIONS AND RECOMMENDATIONS}

In conclusion, it appears that metabolic alkalosis can have deleterious effects, such as significant as metabolic acidosis in prevalent HD patients. In fact, both increase mortality risk. The optimal predialysis serum bicarbonate is still a matter of debate. The 2000 National Kidney Foundation KDOQI guidelines on nutrition state that predialysis serum bicarbonate should be maintained at $22 \mathrm{mEq} / \mathrm{L}$ or higher. ${ }^{28}$ The 2019 review of the same guidelines states that it is reasonable to aim for a goal of $24-26 \mathrm{mEq} / \mathrm{L}$, although this is opinion based because there are no randomized studies. ${ }^{29}$ Improvement of bicarbonate management in HD patients requires that attention be focused on patients with very low predialysis serum bicarbonate $(<18 \mathrm{mmol} / \mathrm{L})$ and high predialysis serum bicarbonate ( $>27 \mathrm{mmol} / \mathrm{l})$.
The clinician should always first address the patient's nutritional status before changing $D_{B I C}$. In patients with low predialysis serum bicarbonate, we must measure postdialysis serum bicarbonate to make sure that alkali is being adequately delivered. If serum bicarbonate increases adequately, the patient's diet and fluid intake must be revised. In this case, excessive animal protein and/or fluid intake should be the cause of low predialysis serum bicarbonate. Only if this tendency cannot be reversed, should we increase $D_{B I C}$. On the other hand, if the patient has high predialysis serum bicarbonate, the priority should be to correct nutritional deficiencies and search for sources of inflammation, as this is more effective than reducing $D_{B I C}{ }^{30,31}$

Tovbin and Sherman ${ }^{32}$ proposed a new solution for treating metabolic acidosis while avoiding postdialysis metabolic alkalosis. They suggest using a variable dialysate bicarbonate, starting with initially

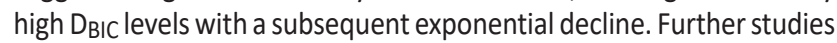
are needed to assess the validity of this method.

Disclosure of potential conflicts of interest: none declared.

\section{References}

1. Kraut JA, Kurtz I. Metabolic acidosis of CKD: Diagnosis, clinical characteristics, and treatment. Am J Kidney Dis. 2005;45(6):978-993. doi:10.1053/j.ajkd.2005.03.003

2. Sam R, Vaseemuddin M, Leong WH, Rogers BE, Kjellstrand CM, Ing TS. Composition and clinical use of hemodialysis. Hemodial Int. 2006;10(1):15-28. doi:10.1111/j.1542-4758.2006.01170.x

3. Tentori F, Karaboyas A, Robinson BM, et al. Association of dialysate bicarbonate concentration with mortality in the Dialysis Outcomes and Practice Patterns Study (DOPPS). Am J Kidney Dis. 2013;62(4):738-746. doi:10.1053/j.ajkd.2013.03.035

4. Basile C, Rossi L, Lomonte C. Dialysate bicarbonate concentration: Too much of a good thing? Semin Dial. 2018;31(6):576-582. doi:10.1111/sdi.12716

5. Adrogué HJ, Gennari FJ, Galla JH, Madias NE. Assessing acid-base disorders. Kidney Int. 2009;76(12):1239-1247. doi:10.1038/ki.2009.359

6. Kraut JA, Nagami GT. The use and interpretation of serum bicarbonate concentration in dialysis patients. Semin Dial. 2014;27(6):577-579. doi:10.1111/sdi.12269

7. Tzanatos H, Dalamangas A, Retsa K, Kapetanaki A, Agroyannis B. Relation of interdialytic water retention with apparent bicarbonate space, $\mathrm{HCO}^{-}$-, and $\mathrm{pH}$ in hemodialyzed uremic patients. Ren Fail. 2005;27(2):235-238. doi:10.1081/JDI-200049542

8. Marano M, Marano S, Gennari FJ. Beyond bicarbonate: Complete acid-base assessment in patients receiving intermittent hemodialysis. Nephrol Dial Transplant. 2017;32(3):528-533. doi:10.1093/ ndt/gfw022

9. Qunibi WY, Nolan CR. Treatment of hyperphosphatemia in patients with chronic kidney disease on maintenance hemodialysis: Results of the CARE study. Kidney Int Suppl. 2004;66(90):33-38. doi:10.1111/j.1523-1755.2004.09006.x

10. J. Delmez, G. Block JR. A randomized, double-blind, crossover design study of sevelamer hydrochloride and sevelamer carbonate in patients on hemodialysis. Clin Nephrol. 2007;68(December):386-391. doi:10.5414/CNP68386

11. Gennari F. Acid-base balance in dialysis patients. Semin Dial. 2000;13(4):235-239. doi:10.1111/ j.1525-139X.1995.tb00339.x

12. Aparicio M, Chauveau P, Azar R, et al. Nutritional status of haemodialysis patients: a French national cooperative study. Nephrol Dial Transplant. 1999;14(April 1996):1679-1686. doi: 10.1093/ ndt/14.7.1679.

13. Pifer TB, McCullough KP, Port FK, et al. Mortality risk in hemodialysis patients and changes in nutritional indicators: DOPPS. Kidney Int. 2002;62(6):2238-2245. doi:10.1046/j.15231755.2002.00658.x

14. Patel R, Paredes $W$, Hall CB, et al. Variability in monthly serum bicarbonate measures in hemodialysis patients: A cohort study. BMC Nephrol. 2015;16(1):1-11. doi:10.1186/s12882-015-0206-2

15. Basile C, Libutti P, Di Turo AL, et al. Effect of dialysate calcium concentrations on parathyroid hormone and calcium balance during a single dialysis session using bicarbonate hemodialysis: A crossover clinical trial. Am J Kidney Dis. 2012;59(1):92-101. doi:10.1053/j.ajkd.2011.08.033

16. Park S, Paredes W, Custodio M, et al. Intradialytic acid-base changes and organic anion production during high versus low bicarbonate hemodialysis. Am J Physiol - Ren Physiol. 2020;318(6): F1418-F1429. doi:10.1152/ajprenal.00036.2020

17. Lowrie EG, Lew NL. Death risk in hemodialysis patients: The predictive value of commonly measured variables and an evaluation of death rate differences between facilities. Am J Kidney Dis. 1990;15(5):458-482. doi:10.1016/\$0272-6386(12)70364-5

18. Bommer J, Locatelli F, Satayathum $S$, et al. Association of predialysis serum bicarbonate levels with risk of mortality and hospitalization in the Dialysis Outcomes and Practice Patterns Study (DOPPS). Am J Kidney Dis. 2004;44(4):661-671. doi:10.1053/j.ajkd.2004.06.008 
19. Wu DY, Shinaberger CS, Regidor DL, McAllister CJ, Kopple JD, Kalantar-Zadeh K. Association between serum bicarbonate and death in hemodialysis patients: Is it better to be acidotic or alkalotic? Clin J Am Soc Nephrol. 2006;1(1):70-78. doi:10.2215/CJN.00010505

20. Fresenius Medical Care North America Medical Office. Dialysate Bicaronate. Published 2011. Accessed June 1, 2020. http://www.renalweb.com/writings/alkalosis/WithinFMC.htm

21. Yamamoto T, Shoji S, Yamakawa T, et al. Predialysis and postdialysis pH and bicarbonate and risk of all-cause and cardiovascular mortality in long-term hemodialysis patients. Am J Kidney Dis. 2015;66(3):469-478. doi:10.1053/j.ajkd.2015.04.014

22. Chang KY, Kim HW, Kim WJ, et al. The impact of high serum bicarbonate levels on mortality in hemodialysis patients. Korean J Intern Med. 2017;32(1):109-116. doi:10.3904/kjim.2015.168

23. Di lorio B, Torraca S, Piscopo C, et al. Dialysate bath and QTc interval in patients on chronic maintenance hemodialysis: Pilot study of single dialysis effects. J Nephrol. 2012;25(5):653-660. doi:10.5301/jn.5000036

24. Gabutti L, Ferrari N, Giudici G, Mombelli G, Marone C. Unexpected haemodynamic instability associated with standard bicarbonate haemodialysis. Nephrol Dial Transplant. 2003;18(11):23692376. doi:10.1093/ndt/gfg383

25. Viegas M, Cândido C, Felgueiras J, et al. Dialysate bicarbonate variation in maintenance hemodiafiltration patients: Impact on serum bicarbonate, intradialytic hypotension and interdialytic weight gain. Hemodial Int. 2017;21(3):385-392. doi:10.1111/hdi.12502

26. Krahn RE, Tulowitzki R, Gudleski GD, et al. Effect of bicarbonate-buffered dialysate on ventricular arrhythmias in hemodialysis patients. Am J Nephrol. 2019;49(1):74-80. doi:10.1159/000495846
27. Harris DCH, Yuill E, Chesher DW. Correcting acidosis in hemodialysis: Effect on phosphate clearance and calcification risk. Nephrology. Published online 1995:1607-1612.

28. Eknoyan G, Levin NW. K/DOQI(TM) clinical practice guidelines for nutrition in chronic renal failure. Am J Kidney Dis. 200; 37(1 Suppl 2):S66-70.

29. National Kidney Foundation. Clinical Practice Guideline for Nutrition in Chronic Kidney Disease: 2019 Update. Acad Nutr Diet. 2019;(October):131-147.

30. Basile C, Rossi L, Lomonte C. The choice of dialysate bicarbonate: Do different concentrations make a difference? Kidney Int. 2016;89(5):1008-1015. doi:10.1016/j.kint.2016.01.010

31. Ponce P. Correcting acidosis in CKD patients: How much is too much. Port J Nephrol Hypertens. 2016;30(2):94-101.

32. Tovbin D, Sherman RA. Correcting acidosis during hemodialysis: Current limitations and a potential solution. Semin Dial. 2016;29(1):35-38. doi:10.1111/sdi.12454

\section{Correspondence to:}

Gonçalo Ávila, MD

Nephrology department, Hospital de Santa Cruz - CHLO, Carnaxide

E-mail: gnr.avila@gmail.com 